\title{
Covid-19 no nordeste do Brasil: entre o lockdown e o relaxamento das medidas de distanciamento social
}

\author{
Covid-19 in the Northeast of Brazil: from lockdown to the \\ relaxation of social distancing measures
}

Ricardo Arraes de Alencar Ximenes (https://orcid.org/0000-0002-9951$8840)^{1,3}$

Maria de Fatima Pessoa Militão de Albuquerque (https://orcid.org/00000002-4999-4160) ${ }^{2}$

Celina Maria Turchi Martelli (https://orcid.org/0000-0002-2491-0688) ${ }^{2}$

Thália Velho Barreto de Araújo (https://orcid.org/0000-0001-9956-4145) ${ }^{1}$

Demócrito de Barros Miranda Filho (https://orcid.org/0000-0003-2537-

1476) ${ }^{3}$

Wayner Vieira de Souza (https://orcid.org/0000-0002-0939-9332) ${ }^{2}$

Maria Yury Travassos Ichihara (https://orcid.org/0000-0001-8590-6212) ${ }^{4}$

Pedro Israel Cabral de Lira (https://orcid.org/0000-0002-1534-1620) ${ }^{1}$

Ligia Regina Franco Sansigolo Kerr (https://orcid.org/0000-0003-4941$408 \mathrm{X})^{5}$

Estela ML Aquino (https://orcid.org/0000-0002-8204-1249) ${ }^{6}$

Antônio Augusto Moura da Silva (https://orcid.org/0000-0003-4968-5138) ${ }^{7}$
Rosa Lívia Freitas de Almeida (https://orcid.org/0000-0001-6423-543X) ${ }^{8}$ Carl Kendall (https://orcid.org/0000-0002-0794-4333) ${ }^{5}$

Julia M Pescarini (https://orcid.org/0000-0001-8711-9589) ${ }^{4}$

Sinval Pinto Brandão Filho (https://orcid.org/0000-0003-3768-2810) ${ }^{2}$

Naomar Almeida-Filho (https://orcid.org/0000-0002-4435-755X) ${ }^{6}$

Juliane Fonseca de Oliveira (https://orcid.org/0000-0002-7167-8754) ${ }^{4}$

Carlos Teles (https://orcid.org/0000-0003-0970-0479) ${ }^{4}$

Daniel Cardoso Pereira Jorge (https://orcid.org/0000-0003-4707- 3234) ${ }^{6}$

Guilherme Santana (https://orcid.org/0000-0001-7860-2739) ${ }^{4}$

Ligia Gabrielli (https://orcid.org/0000-0002-5195-1979) ${ }^{6}$

Moreno MS Rodrigues (https://orcid.org/0000-0002-1594-2311) ${ }^{9}$

Natanael Jesus da Silva (https://orcid.org/0000-0003-3002-1032) ${ }^{4}$

Rafael Felipe da Silva Souza (https://orcid.org/0000-0002-0484-0782) ${ }^{4}$

Vivian Alessandra Ferreira da Silva (https://orcid.org/0000-0002-9893-1895) ${ }^{4}$ Maurício Lima Barreto (http://orcid.org/0000-0002-0215-4930) ${ }^{4}$
${ }^{1}$ Universidade Federal de Pernambuco. Av. Prof. Moraes Rêgo s/n, Cidade Universitária. 50670420 Recife PE Brasil. raaximenes@uol.com.br ${ }^{2}$ Instituto Aggeu Magalhães, Fiocruz. Recife PE Brasil.

${ }^{3}$ Universidade de

Pernambuco. Recife PE

Brasil.

${ }^{4}$ Centro de Integração de Dados e Conhecimentos para Saúde, Instituto

Gonçalo Moniz, Fiocruz Bahia. Salvador BA Brasil.

${ }^{5}$ Universidade Federal do Ceará. Fortaleza CE Brasil.

${ }^{6}$ Universidade Federal da Bahia. Salvador BA Brasil. ${ }^{7}$ Universidade Federal do Maranhão. São Luís MA Brasil.

${ }^{8}$ Universidade de Fortaleza. Fortaleza CE Brasil.

${ }^{9}$ Fiocruz Rondônia. Porto

Velho RO Brasil.
Abstract Even in the period when the Covid-19 pandemic was on the rise in the Northeast of Bra$z i l$, the relaxation of social distancing measures was introduced. The scope of the study is to assess, in the light of the epidemiological-sanitary situation in the region, the suitability of relaxation of social distancing measures. Based on the WHO guidelines for relaxation of social distancing, operational indicators were created and analyzed for each guideline in the context of the Northeast. To analyze the behavior of the epidemic, according to selected indicators, Joinpoint trend analysis techniques, heat maps, rate ratios and time trends between capitals and the state interior were compared. The weekly growth peak of the epidemic occurred in May-July 2020 (epidemiological weeks 19 to 31). In most capitals, there was no simultaneous downward trend in the number of cases and deaths in the 14 days prior to flexibilization. In all states the number of tests performed was insufficient. In epidemiological week 24, the state percentages of ICU/Covid-19 bed occupancy were close to or above $70 \%$. The epidemiological situation of the nine Northeastern state capitals analyzed here did not meet criteria and parameters recommended by the World Health Organization for the relaxation of social distancing measures.

Key words Covid-19, Social Distancing, Coronavirus, Northeast Brazil, Epidemic
Resumo Mesmo no período em que a pandemia de Covid-19 encontrava-se em crescimento no Nordeste do Brasil, iniciou-se a adoção de medidas de flexibilização do distanciamento social. $O$ objetivo do estudo é o de avaliar a pertinência das propostas de flexibilização, tomando-se em conta a situação da pandemia em cada local e o momento em que foram adotadas. Tendo como referência as diretrizes da OMS, foram construídos e analisados indicadores operacionais para cada diretriz, no contexto da região Nordeste. Para análise do comportamento da epidemia, conforme indicadores selecionados, foram usadas técnicas de Joinpoint Trend Analysis, mapas de calor, razão de taxas e comparação da tendência temporal entre capitais e interior dos estados. O pico do crescimento semanal ocorreu em maio-julho/2020 (semanas epidemiológicas 19 a 31). Na maioria das capitais não se observou tendência decrescente simultânea do número de casos e óbitos nos 14 dias prévios à flexibilização. Em todos os estados o quantitativo de testes realizados foi insuficiente. Na semana epidemiológica 24 os percentuais estaduais de ocupação de leitos de UTI/Covid-19 foram próximos ou superiores $70 \%$. A situação epidemiológica das nove capitais dos estados do Nordeste, no momento em que a decisão de flexibilização foi tomada, mostra que nenhuma delas atendia aos critérios $e$ parâmetros recomendados pela OMS.

Palavras-chave Covid-19, Distanciamento Social, Coronavirus, Nordeste Brasil, Epidemia 


\section{Introdução}

Desde que a Organização Mundial de Saúde (OMS) declarou a existência de uma pandemia pelo SARS-CoV-2, em 11 de março de 2020, o número de casos relatados de Covid-19 no mundo passou de 118 mil para mais de 37 milhões, e o de mortes pela doença de 4.200 para mais de 1 milhão, em 11 de outubro de $2020^{1}$.

A partir da experiência da China, que aplicou medidas severas de restrição da circulação de pessoas em toda a província de Hubei, ficou demonstrada a efetividade do distanciamento social rigoroso. Essa medida, combinada com testagem em massa, isolamento dos casos e rastreamento intensivo de contatos, interrompeu a cadeia de transmissão, controlando o surto ${ }^{2}$. O distanciamento social - fechamento de unidades de ensino, locais de trabalho, estabelecimentos comerciais ou religiosos, restrição de meios de transporte públicos e cancelamento de eventos com aglomeração de pessoas - são medidas destinadas a reduzir interações interpessoais e, como consequência restringem a transmissão do SARS-CoV-2 $2^{3-6}$.

Países da Europa, como a Itália, Espanha e Reino Unido, variaram em sua interpretação da necessidade do distanciamento social e mesmo de quando iniciá-lo. Fazia-se presente a preocupação com o impacto da epidemia da Covid-19 sobre a economia, até que a crise sanitária deteriorou e as projeções geradas por modelos matemáticos ${ }^{4}$ levaram a um crescente consenso nos meios acadêmicos e nos gestores públicos: seria necessário recorrer às medidas de distanciamento social, como única alternativa capaz de conter a pandemia e reduzir os seus efeitos, em especial casos graves e óbitos e o caos do sistema de saúde.

No entanto, ao contrário das medidas rigorosas implementadas em Hubei, o distanciamento social teve suas adaptações em cada local em que foi adotado, na dependência das diferenças culturais ou de decisões políticas dos governantes. $\mathrm{Na}$ Europa, sem um padrão uniforme de implementação entre os diversos países, variou com a implementação de estratégias diversificadas e com diferentes percentuais de adesão. Tendo, em alguns países, chegado ao lockdown completo, que inclui a proibição das pessoas saírem de casa, exceto para comprar suprimentos básicos ou para acessar serviços de saúde. As evidências mostram ser essa a medida mais efetiva para conter a disseminação do SARS-CoV-2, até que se disponha de uma vacina ou de tratamentos eficazes ${ }^{2,3,7}$.
No Brasil, assistimos a tríplice crise enfrentada pela população: sanitária, econômica e política. O não reconhecimento da pandemia como uma grande ameaça à população pelo governo federal, com mensagens contrárias às experiências acumuladas em vários países e às recomendações da OMS, e as repetidas trocas de comando do Ministério da Saúde, têm dificultado o controle da pandemia no país ${ }^{3}$. Ademais, a pandemia encontrou um país onde duras medidas de cunho neoliberais (socioeconômicas e políticas) contribuíram para sua imersão num período de estagnação econômica, amplificada por fortes restrições do uso de recursos públicos para financiar políticas sociais, com o agravamento do subfinanciamento do Sistema Único de Saúde em razão do teto de gastos para saúde e educação, imposto pela PEC 95/16 ${ }^{8}$. Sabe-se também, que a efetivação das medidas de distanciamento social requer a adoção concomitante de políticas, da alçada do governo federal, de proteção social aos segmentos mais vulneráveis; medidas imprescindíveis em razão da desigualdade social e da pobreza, e do amplo contingente da população $(41,3 \%)$ inserido no mercado informal de trabalho e submetido às precárias condições de moradia ${ }^{9}$.

Esse cenário levou o Consórcio de Governadores do Nordeste a adotar de forma coordenada e independente do governo federal medidas e ações de enfrentamento da Covid-19 na Região. Em março de 2020, uma série de medidas foram adotadas pelos governadores e prefeitos da região, que foram efetivas em ampliar o distanciamento e conter o ímpeto inicial da epidemia ${ }^{10}$. Mesmo com a pandemia ainda em crescimento, teve início o debate relacionado à flexibilização das medidas de distanciamento social e à reabertura das atividades econômicas (comércio, da rede de prestação de serviços e outras atividades laborais).

O objetivo do estudo é o de avaliar, à luz da situação epidemiológico-sanitária da região, a pertinência das propostas de flexibilização do distanciamento social, tomando-se em conta a situação da pandemia em cada local e momento em que foram adotadas. Para isto referencia-se as recomendações e diretrizes da $\mathrm{OMS}^{11}$ para definir as condições propicias à implementação de medidas de flexibilização e retomada das atividades laborais, educacionais e de lazer, guiada por princípios de saúde pública. 


\section{Métodos}

\section{Local de estudo}

A região Nordeste do Brasil, abrange nove estados: Alagoas (AL), Bahia (BA), Ceará (CE), Maranhão (MA), Paraíba (PB), Pernambuco (PE), Piauí (PI), Rio Grande do Norte (RN) e Sergipe (SE), com população estimada em 53 milhões de habitantes e área geográfica de aproximadamente 1,5 milhões de $\mathrm{Km}^{212}$.

\section{Produção dos dados}

Os dados demográficos foram obtidos do Instituto Brasileiro de Geografia e Estatística $(\mathrm{IBGE})^{12}$.

Os dados para as capitais dos estados do Nordeste brasileiro são referentes ao período do início da epidemia até a semana epidemiológica 36 (30 de agosto à 05 de setembro de 2020). Os casos de Covid-19 confirmados e os óbitos são provenientes do Ministério da Saúde e Secretarias Estaduais, disponíveis em repositório de dados abertos ${ }^{13}$.

Os dados sobre a circulação de pessoas são provenientes do índice de isolamento social da agência Inloco ${ }^{14}$, que a partir de 01/02/2020 monitora a parcela da população que está atendendo à recomendação de distanciamento social nos estados e municípios brasileiros. O Índice Inloco por meio de dados capturados por telefones celulares estima o percentual diário da população que não deixou o local de residência (inferido a partir da tecnologia Inloco) em relação ao total de usuários na área de residência.

Nas capitais dos estados do Nordeste o início das medidas de flexibilização do distanciamento social ocorreu entre a semana epidemiológica 20 e 30, para efeito de comparabilidade alguns resultados são apresentados tendo por referência a semana epidemiológica 24

À luz das recomendações da $\mathrm{OMS}^{11}$ foram construídos indicadores para operacionalizar as diretrizes (números de 1 a 6 ) e estratégias propostas na perspectiva de analisar a adequação e oportunidade da decisão governamental em estabelecer a flexibilização do distanciamento social nas capitais dos estados da Região Nordeste (Quadro 1).

\section{Análise dos Dados}

\section{Comparação da situação epidemiológica antes e após o início das medidas de flexibilização do distanciamento social}

A análise da série histórica do acumulado semanal de casos confirmados da Covid-19 foi feita com emprego do aplicativo JoinPoint Trend Analysis $^{15}$. Em síntese, esse programa analisa dados de séries históricas buscando identificar pontos de inflexão nessas curvas. O programa é inicializado com o número mínimo de pontos de inflexão (por exemplo, 0 pontos, que representa uma linha reta) e testa se mais pontos de inflexão são estatisticamente significativos e devem ser adicionados ao modelo. Isso permite ao usuário testar se uma aparente mudança de tendência é estatisticamente significativa. Os testes de significância usam o método de permutação de Monte Carlo. Os modelos podem incorporar variação estimada para cada ponto (por exemplo, quando as respostas são taxas ajustadas por idade), ou usar um modelo de variação de Poisson, o que foi usado na presente análise. Além disso, os modelos também podem ser lineares no log da resposta $\left(\operatorname{Ln}(y)=\beta_{0}+\beta_{1} t\right)$, como aqui utilizado, para calcular a alteração da taxa percentual semanal ${ }^{16}$.

Os dados de notificações de casos e óbitos confirmados por Covid-19 para as capitais do Nordeste foram plotados como mapas de calor (Heatmaps). É uma visualização em formato matricial, ou seja, $\mathrm{M} \times \mathrm{N}$, na qual $\mathrm{M}$ representou as semanas epidemiológicas e $\mathrm{N}$ as capitais. Os mapas são compostos por caselas quadriculares preenchidas com intensidade de cores, sendo as menores grandezas mapeadas com cores mais claras, e as maiores, com cores mais escuras. Cada semana epidemiológica tem a soma do total de casos ou óbitos diários ou taxa de incidência ou taxa de mortalidade por 100.000 hab ocorridos nesse período. A plotagem realizada levou em consideração os dados captados até o encerramento da semana epidemiológica 36 ( 05 de setembro).

Para cada capital foram calculadas razões de taxas para as taxas de incidência e mortalidade da semana epidemiológica correspondente ao início da flexibilização do distanciamento social com as taxas de duas semanas anteriores ao início da flexibilização. Valores menores do que 1 indicariam que a taxa estaria decrescendo; valor maior do que 1 mostra uma situação inversa e igual a 1 a estabilidade das taxas.

$\mathrm{Na}$ análise da tendência temporal da epidemia e comparação entre as capitais, as regiões metropolitanas (sem as capitais) e o interior dos 
Quadro 1. Diretrizes e indicadores para subsidiar a decisão de flexibilização do distanciamento social.

\begin{tabular}{|c|c|}
\hline Diretrizes & Indicadores \\
\hline $\begin{array}{l}\text { 1. Existência de evidência de } \\
\text { controle da transmissão do } \\
\text { Covid-19 }\end{array}$ & $\begin{array}{l}\text { 1.1. Tendência decrescente do número de casos notificados de Covid-19, pelo } \\
\text { menos por } 14 \text { dias consecutivos;- } \\
\text { 1.2. Tendência decrescente do número de óbitos no sistema de notificação } \\
\text { Covid-19, pelo menos por } 14 \text { dias consecutivos; } \\
\text { 1.3. Rt }<1 \text { por um período de } 14 \text { dias ou, na ausência dessa informação, razão de } \\
\text { incidência }<1 \text { entre as duas semanas epidemiológicas subsequentes em relação à } \\
\text { semana do início da avaliação. }\end{array}$ \\
\hline $\begin{array}{l}\text { 2. Que a saúde pública } \\
\text { tenha capacidade para } \\
\text { identificar, isolar, testar } \\
\text { e rastrear contatos para } \\
\text { estabelecer quarentena; } \\
\text { que os estabelecimentos de } \\
\text { saúde incluindo hospitais } \\
\text { tenham leitos disponíveis. }\end{array}$ & $\begin{array}{l}\text { 2.1. Vigilância Epidemiológica com capacidade para detectar casos na população } \\
\text { geral e em populações especiais, que são aquelas com alto potencial de transmissão } \\
\text { como, por exemplo, profissionais de saúde, profissionais de transporte urbano, } \\
\text { profissionais ligados à distribuição de alimentos, etc. Garantir a disponibilidade } \\
\text { de testes em número adequado e logística necessária para realização dos mesmos. } \\
\text { Garantir também o rastreamento de contatos, tanto pelas estruturas da Vigilância } \\
\text { Epidemiológica, quanto pelas redes de atenção primária à saúde, apoiadas pela } \\
\text { Estratégia de Saúde da Família; } \\
\text { 2.2. Disponibilizar locais para isolamento de contatos positivos sem condições de } \\
\text { isolamento domiciliar; } \\
\text { 2.3. Ter pelo menos } 30 \% \text { de leitos de UTI disponíveis, indicando capacidade } \\
\text { instalada e disponibilidade de recursos humanos treinados para atendimento; } \\
\text { 2.4. Definir áreas com diferentes níveis de vulnerabilidade com base na tendência } \\
\text { do número de casos e de óbitos, número de leitos hospitalares/UTI, disponíveis na } \\
\text { área geográfica correspondente e condições socioeconômicas (IBGE); }\end{array}$ \\
\hline $\begin{array}{l}\text { 3. Que o risco de surto } \\
\text { seja minimizado em locais } \\
\text { de alta vulnerabilidade - } \\
\text { particularmente em abrigos } \\
\text { - residências coletivas com } \\
\text { aglomeração populacional } \\
\text { (idosos; abrigos } \\
\text { governamentais, prisões, } \\
\text { moradores de rua etc.) }\end{array}$ & $\begin{array}{l}\text { 3.1. Estabelecer vigilância ativa em locais de alto risco de transmissão e/ou com } \\
\text { população vulnerável complementado pelo isolamento dos positivos; } \\
\text { 3.2. Realização de teste moleculares (PCR) para rastreamento e isolamento de } \\
\text { casos assintomáticos e contatos positivos; } \\
\text { 3.3. Avaliar imunidade de grupo com realização periódica de testes sorológicos. }\end{array}$ \\
\hline $\begin{array}{l}\text { 4. Que as medidas de } \\
\text { controle preventivas dos } \\
\text { locais de trabalho tenham } \\
\text { sido estabelecidas - com } \\
\text { distanciamento social, locais } \\
\text { para lavar as mãos, etiqueta } \\
\text { respiratória. }\end{array}$ & $\begin{array}{l}\text { 4.1. Garantir que nos locais de trabalho e escolas, as instalações estejam } \\
\text { adequadas antes da reabertura e incluir a obrigatoriedade do uso de máscara e a } \\
\text { observância do distanciamento físico recomendado; } \\
\text { 4.2. Realizar testes PCR em sintomáticos respiratórios e seus contatos próximos, } \\
\text { no local de trabalho e domicílio. }\end{array}$ \\
\hline $\begin{array}{l}\text { 5. Que os riscos externos } \\
\text { possam ser gerenciados }\end{array}$ & $\begin{array}{l}\text { 5.1. Redução de risco de transmissão por bloqueio/interrupção temporária } \\
\text { de mobilidade em geral. Analisar o caminho espaço-tempo (semanas } \\
\text { epidemiológicas) já percorrido pela epidemia em nível local (centro > periferia } \\
\text { das Regiões Metropolitanas das capitais) e no nível estadual (capital > interior), } \\
\text { construindo os cenários de propagação da epidemia visando subsidiar as ações } \\
\text { de controle; } \\
\text { 5.2. Construir mapas de fluxos de deslocamento para o nível local (trabalho, } \\
\text { escolas, etc.) e para o nível estadual (rodovias, acesso aos polos de importância } \\
\text { econômica, etc.), para subsidiar decisões; } \\
\text { 5.3. Quarentena para pessoas que chegam de áreas com circulação do SARS- } \\
\text { CoV-2, por } 14 \text { dias. }\end{array}$ \\
\hline $\begin{array}{l}\text { 6. Que a sociedade tenha } \\
\text { voz e esteja engajada na } \\
\text { transição }\end{array}$ & $\begin{array}{l}\text { 6.1. Assegurar que a sociedade participe dos processos de discussão e decisão } \\
\text { estabelecendo a retomada de atividades relacionadas ao trabalho, educação e } \\
\text { lazer. Envolver no processo os Conselhos Estaduais de Saúde e representações da } \\
\text { sociedade civil. }\end{array}$ \\
\hline
\end{tabular}


estados realizou-se a transformação logarítmica das taxas de incidência acumulada da infecção pelo coronavírus.

\section{Resultados}

\section{Situação das capitais dos estados do Nordeste em relação aos indicadores operacionais 1.1 e 1.2 (Tendência decrescente do número de casos notificados e de óbitos pela Covid-19, em pelo menos uma série temporal de 14 dias)}

O primeiro estado do Nordeste a notificar casos de Covid-19 foi o Ceará, em 15 de março, seguido por questão de dias pelos outros estados até que o último, o Maranhão, o fizesse em 20 de março. As medidas de distanciamento social foram quase todas implementadas nos estados da Região durante o mês de março ${ }^{10}$.

Com relação às capitais, observa-se que o período de pico do crescimento semanal de casos, com variações entre as diferentes capitais, ocorreu entre maio e julho de 2020 (Figura 1). A partir daí verifica-se tendência a desaceleração no crescimento, porém com flutuação dos valores em algumas capitais.

Os dados apresentados no mapa de calor com os casos confirmados e acumulados mostram em números absoltos a magnitude da epidemia, destacando-se, Salvador-BA e Fortaleza-CE, com, respectivamente, 79.074 e 47.455 casos acumulados até a semana epidemiológica 36 . Os dados também permitem visualizar que o número de casos é elevado, variando, na semana 36, de 366 casos em Maceió-AL até 2.826 em Salvador-BA. (Figura 2) Com relação ao número acumulado de óbitos, chamam a atenção o Fortaleza-CE, com mais de 3.000, Recife-PE e Salvador-BA com mais de 2.000 óbitos até a semana 36; nesta semana o número de óbitos, variou de 7 em São Luís-MA a 50 em Salvador-BA (Figura 2).

No momento do início da flexibilização das medidas de distanciamento social seis apresentavam uma tendência decrescente do número de casos, duas (Natal-RN e João Pessoa-PB) encontravam-se no pico de incidência e uma (AracajúSE) ainda apresentava tendência crescente (Figura 1 e Figura 2)

\author{
Situação das capitais dos estados \\ do Nordeste em relação aos indicadores \\ operacionais 1.3 (razão de incidência e de \\ óbitos de duas semanas epidemiológicas \\ subsequentes em relação à semana do início \\ da avaliação é <1)
}

Com base nos dados apresentados nos mapas de calor (Figura 2) calculou-se as razões de taxas de incidência e mortalidade verificando-se que apenas uma (Recife), dentre as nove capitais, apresentou ambas as razões de taxas de incidência e de mortalidade inferior a 1 , indicando ter havido redução no risco de adoecimento e de morte pela Covid-19 na semana do início da flexibilização e na semana anterior (dados não apresentados).

\section{Situação dos estados do Nordeste em relação ao indicador operacional 2.1 (Vigilância Epidemiológica com capacidade para detectar casos na população geral e em populações especiais)}

Nos estados o quantitativo de testes realizados se mostrou insuficiente para assegurar a detecção dos casos e dimensionar a epidemia. Os estados que realizaram maior número de teste para diagnóstico da Covid-19 foram Pernambuco, com aproximadamente 50 mil testes realizados em uma população de mais de 9 milhões, Bahia e Ceará, em torno de 70 mil testes em uma população superior a 15 milhões e 9 milhões, respectivamente, e Maranhão com aproximadamente 100 mil testes em uma população de mais de 7 milhões.

\section{Situação dos estados do Nordeste em relação ao indicador operacional 2.3 \\ (Ter pelo menos $30 \%$ de leitos de UTI disponíveis, indicando capacidade instalada e disponibilidade de recursos humanos treinados para atendimento)}

Em todos os estados da região Nordeste há grande concentração de leitos de UTI nas capitais e nos grandes centros urbanos. Em dezembro de 2019, informações obtidas junto ao Cadastro Nacional de Estabelecimentos de Saúde (CNES) mostram elevados percentuais de Leitos de UTI nas Capitais, com os seguintes valores, Alagoas $67 \%$, Bahia 55\%, Ceará 67\%, Maranhão 53\%, Paraíba 45\%, Pernambuco 66\% e Sergipe $86 \%{ }^{17}$. 

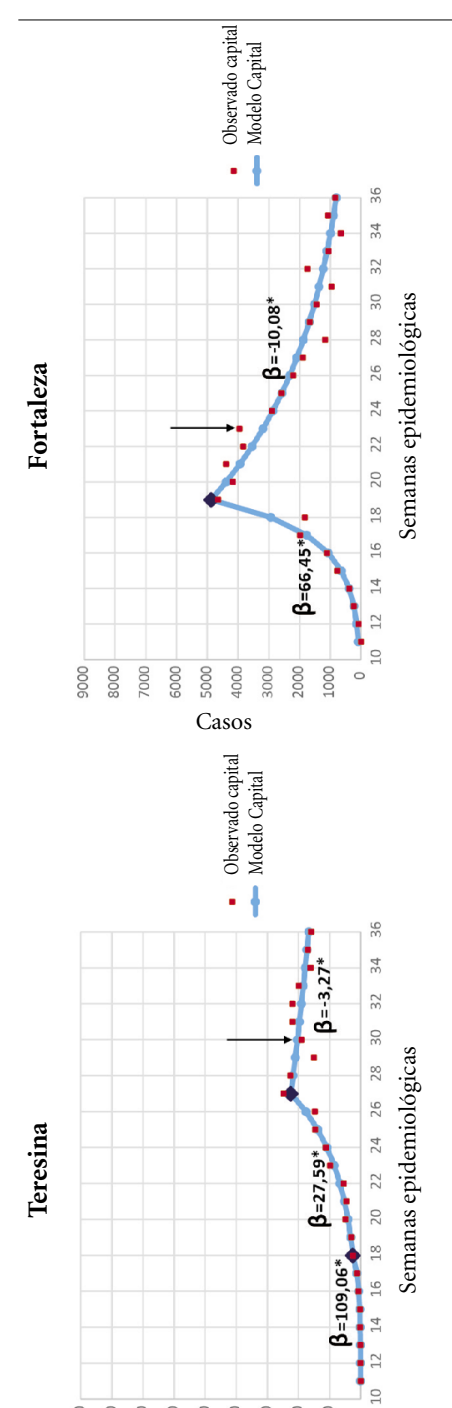

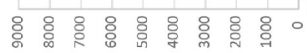

Casos

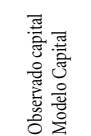

- 1

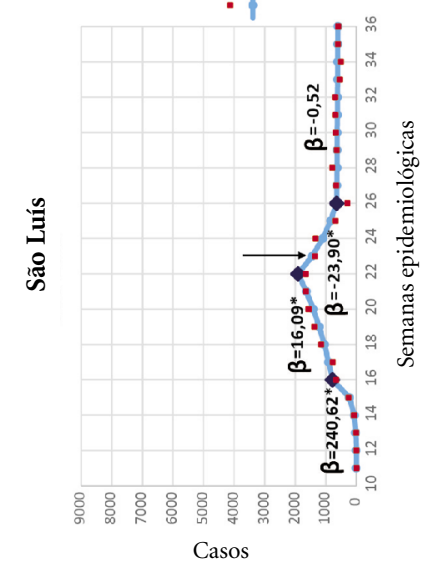

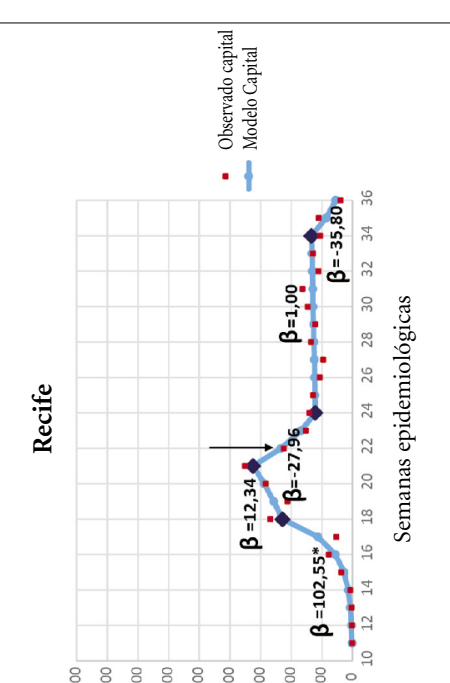
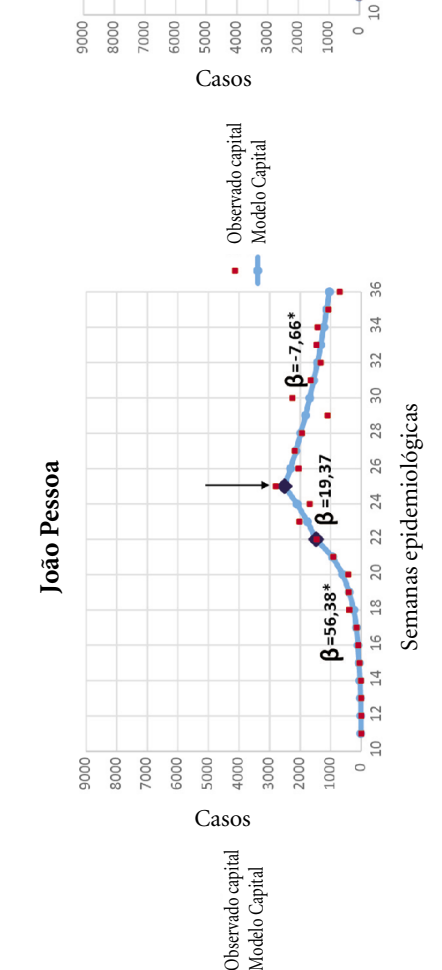

$\cdot 1$

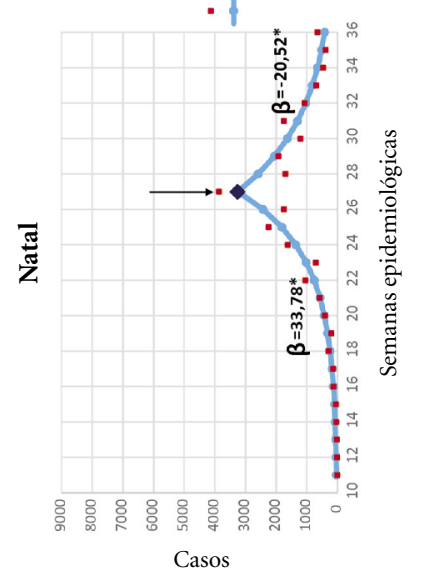

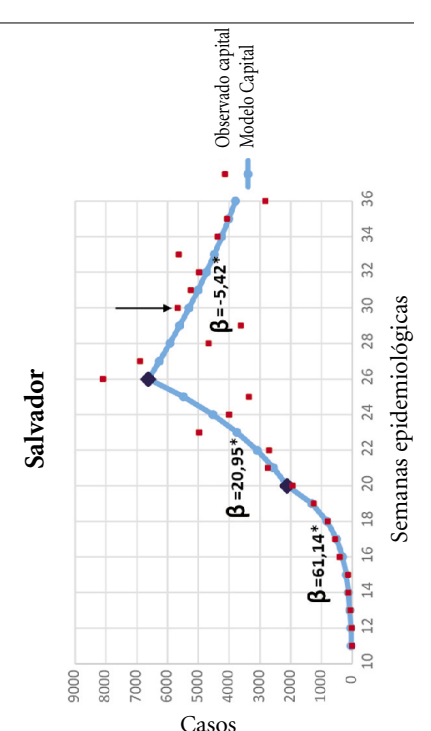
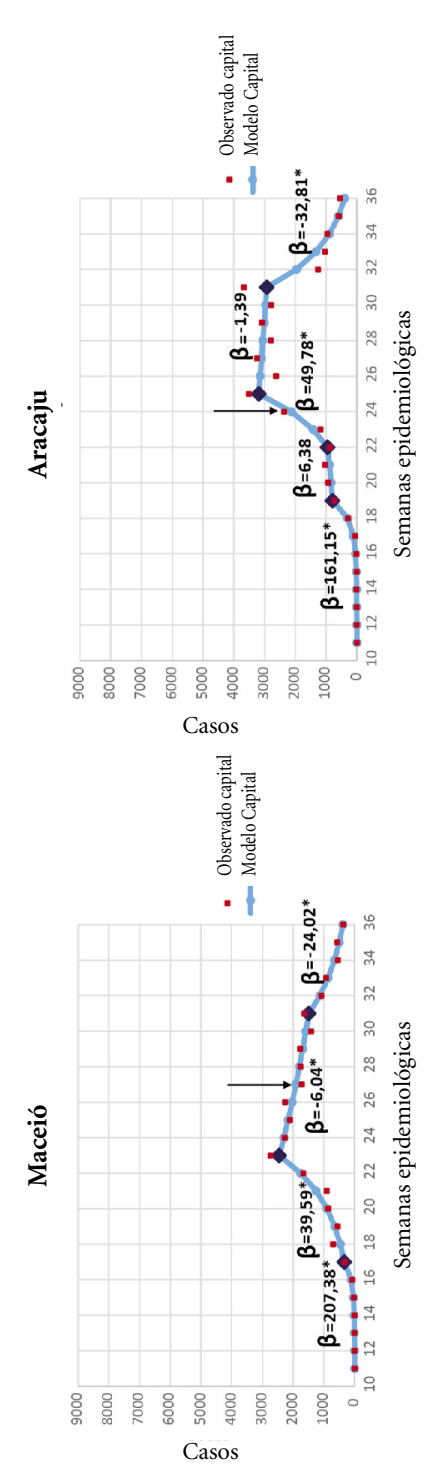

Figura 1 . Velocidade de crescimento semanal e períodos de inflexão da curva epidêmica nas capitais dos estados do Nordeste do Brasil, Março - Setembro, 2020. 
$\begin{array}{lllllllllllllllllllllllllll}10 & 11 & 12 & 13 & 14 & 15 & 16 & 17 & 18 & 19 & 20 & 21 & 22 & 23 & 24 & 25 & 26 & 27 & 28 & 29 & 30 & 31 & 32 & 33 & 34 & 35 & 36\end{array}$

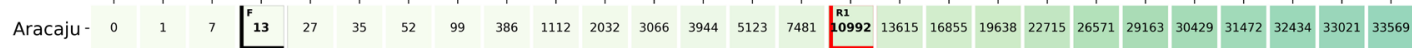

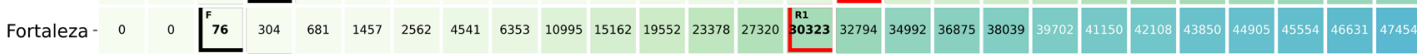

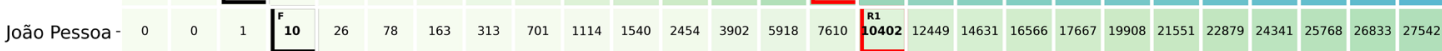

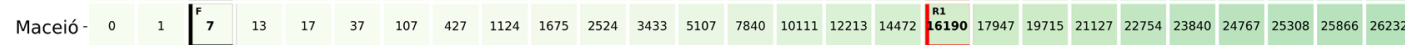

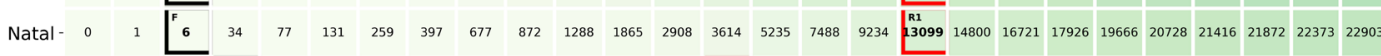

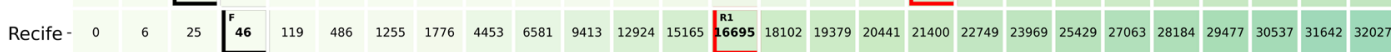

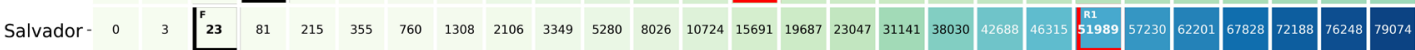

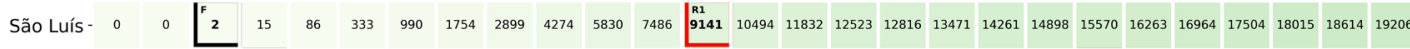

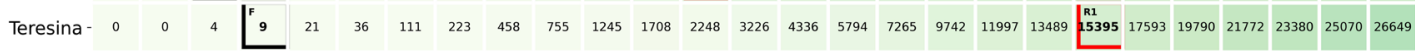

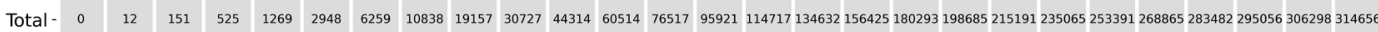
Casos Acumulados

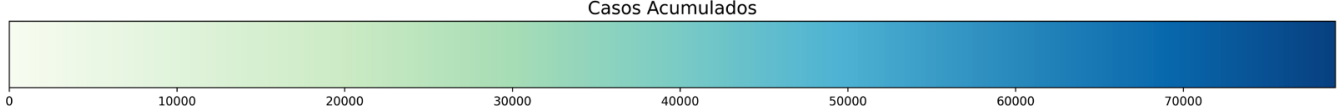

$\begin{array}{llllllllllllllllllllllllllll}10 & 11 & 12 & 13 & 14 & 15 & 16 & 17 & 18 & 19 & 20 & 21 & 22 & 23 & 24 & 25 & 26 & 27 & 28 & 29 & 30 & 31 & 32 & 33 & 34 & 35 & 36\end{array}$

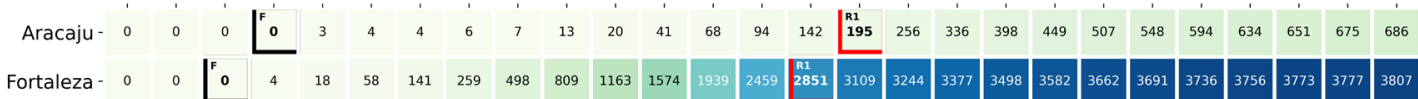

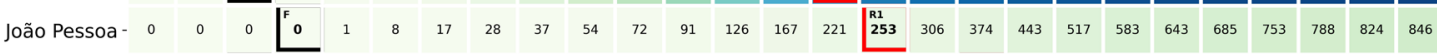

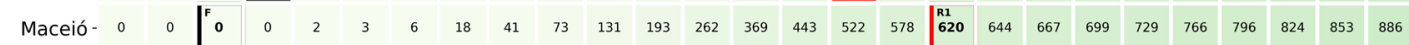
\begin{tabular}{|c|c|c|c|c|c|c|c|c|c|c|c|c|c|c|c|c|c|c|c|c|c|c|c|c|c|c|c|}
\hline Natal- & 0 & 0 & 0 & 0 & 1 & 3 & 5 & 9 & 12 & 19 & 36 & 50 & 100 & 140 & 183 & 262 & 343 & $\mathbf{5 0 6}$ & 589 & 663 & 707 & 829 & 853 & 887 & 930 & 962 & 971 \\
\hline
\end{tabular}

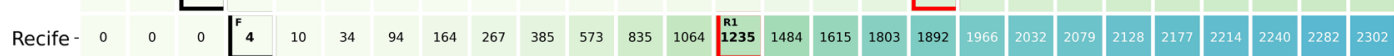

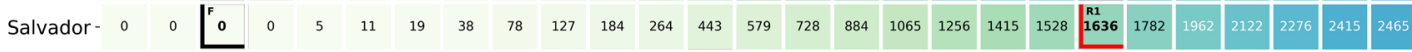

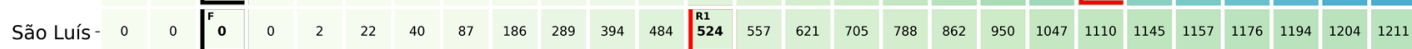

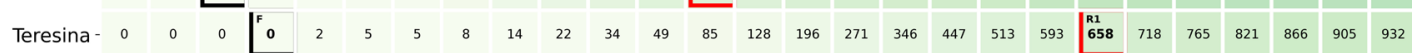

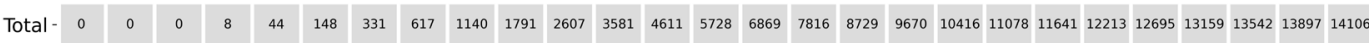
Óbitos Acumulados

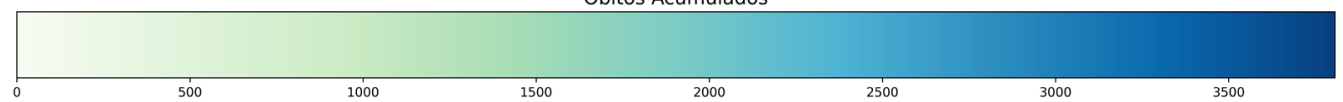

$\begin{array}{lllllllllllllllllllllllllll}10 & 11 & 12 & 13 & 14 & 15 & 16 & 17 & 18 & 19 & 20 & 21 & 22 & 23 & 24 & 25 & 26 & 27 & 28 & 29 & 30 & 31 & 32 & 33 & 34 & 35 & 36\end{array}$

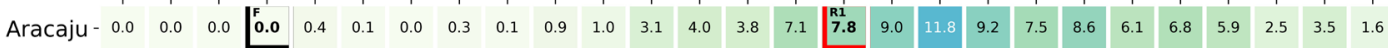

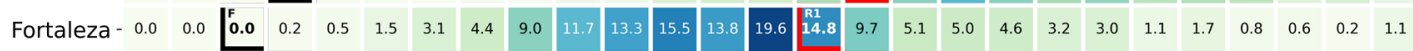

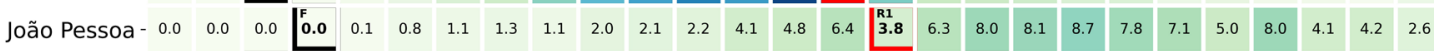

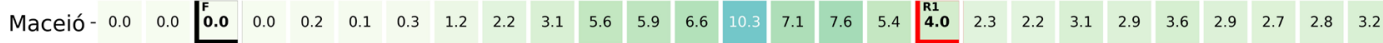

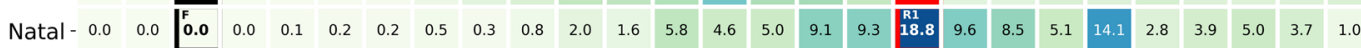

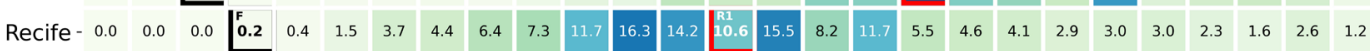

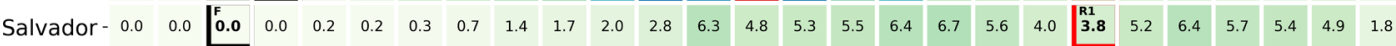

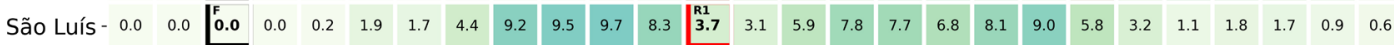

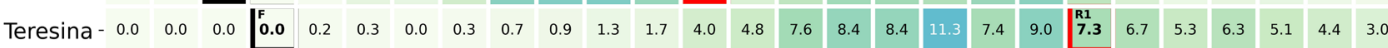

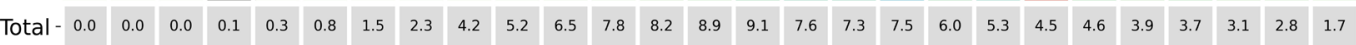
Taxa de Mortalidade / 100.000

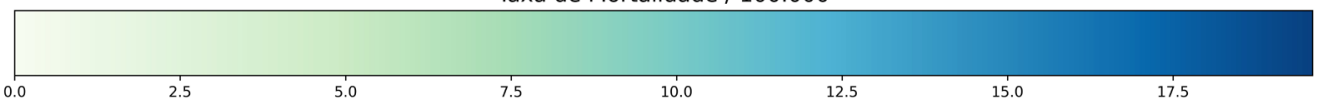

Figura 2. Número de casos e de óbitos por COVID-19 confirmados e acumulados e taxa de mortalidade por semana epidemiológica nos Estados do Nordeste do Brasil, 2020.

Fonte: Óbitos- Cota, W. Wesley Cota, 2020. Monitoramento do número de casos de COVID-19 no Brasil. Disponivel em : < https: // covid19br. wcota.me/>, Acesso em:15.06.2020

População- Freire, H.M.A., Gonzaga, M.R., Gomes, M.M.F. Projeções populacionais por sexo e idade para pequenas áreas no Brasil.Disponível em: https://revistarelap.org/index.php/relap/article/view/231 
Na semana epidemiológica 24, aproximadamente o ponto intermediário entre as semanas nas quais houve o início da flexibilização nas capitais do Nordeste, apenas dois estados, Piauí $(60,8 \%)$ e Paraíba $(65,0 \%)$, apresentavam percentuais de ocupação de leitos de UTI, exclusivos para Covid-19, inferiores, porém próximos a 70\%. Para a maioria dos estados, a taxa de ocupação excedia esse valor: Alagoas $(86,0 \%)$, Ceará $(90,0 \%)$, Rio Grande do Norte $(77,0 \%)$, Pernambuco $(94,0 \%)$, Bahia (76,0\%), Sergipe $(74,6 \%)$ e o Maranhão (78,7\%, para a grande ilha; $85,2 \%$ para Imperatriz e $88,4 \%$ para as demais regiões $)^{18-26}$.

\section{Situação dos estados do Nordeste em relação ao indicador operacional 5.1 (Redução de risco de difusão da epidemia no nível estadual (capital>interior), construindo os cenários de propagação da epidemia)}

A Figura 3 apresenta os dados desagregados para capital, região metropolitana e interior dos estados do Nordeste, evidenciando que no período observado a epidemia estava em estágio mais avançado e progrediu de forma mais rápida nas capitais, que apresentam incidência acumulada da Covid-19 maior do que o interior dos estados. Entretanto, a doença mostrava incidência acumulada crescente no interior, notadamente, nos estados de Alagoas, Ceará, Maranhão e Paraíba, caracterizando a interiorização da epidemia. A Figura 4 mostra a expansão geográfica e temporal da epidemia nos municípios da Região Nordeste até a Semana epidemiológica 24.

\section{Comportamento da Epidemia após o início da flexibilização das medidas de distanciamento social}

Apesar da diversidade do curso da epidemia após o início da flexibilização, podem ser identificados pelo menos quatro padrões.

Padrão 1: Observado em Recife e São Luís. O início da flexibilização ocorreu uma (São Luís) a duas semanas (Recife) após o pico da epidemia. A tendência decrescente se manteve por duas (Recife) a três (São Luís) semanas, seguindo-se um período de platô de aproximadamente 10 semanas. A velocidade da queda não diferiu muito nas duas capitais. Com relação à mortalidade observa-se uma flutuação das taxas, em Recife após quatro semanas começa a decrescer enquanto que em São Luís a queda acontece após seis semanas.
Padrão 2: Observado em Natal e João Pessoa. $\mathrm{O}$ início da flexibilização ocorreu no momento de pico da incidência, observando-se, então, tendência decrescente constante, mais acentuada em Natal. Para Natal o pico da mortalidade aconteceu simultaneamente ao pico da incidência, permanecendo alta, embora com flutuações, por mais quatro semanas. Em João Pessoa, a mortalidade permaneceu em platô por oito semanas.

Padrão 3: Observado em Fortaleza, Salvador, Teresina e Maceió. O início da flexibilização ocorreu quatro a cinco semanas após o pico da incidência, sendo um pouco menor para Teresina (3 semanas). A tendência decrescente se manteve em todas as capitais desse grupo, sendo que em Maceió ela se acentua após algumas semanas. Para essas capitais o pico de mortalidade ocorreu antes do início da flexibilização variando o comportamento pós flexibilização, observandose tendência decrescente apenas em Fortaleza, enquanto que nas demais capitais ocorreu uma flutuação das taxas por período de pelo menos quatro semanas. O platô de mortalidade ocorreu em patamares diferentes, sendo mais baixo em Maceió.

Padrão 4: Observado em Aracaju. O início da flexibilização ocorreu quando a incidência e a mortalidade ainda apresentavam tendência crescente. Aproximadamente duas semanas após, os níveis de incidência passam a configurar um platô que irá permanecer por quatro semanas. A mortalidade atinge o pico duas semanas após o início da flexibilização, seguindo-se um período de platô por mais cinco semanas.

O Índice de isolamento social (Inloco) para seis das nove capitais atingiu valores máximo entre 55 e 60\%, enquanto que em São Luís-MA, Natal-RN e Aracajú-SE esses valores foram entre 55 e 55\%. Ressalte-se que em todas as capitais o Índice de isolamento já vinha decrescendo e que a decretação da flexibilização não alterou essa tendência (Figura 5).

\section{Discussão}

Os indicadores propostos evidenciam, de modo inequívoco, que, ao início da flexibilização do distanciamento social, na maioria das capitais dos estados do Nordeste, o número de casos e as taxas de incidência, assim como o número de óbitos e taxas de mortalidade, não apresentavam tendência consistente de decréscimo. 


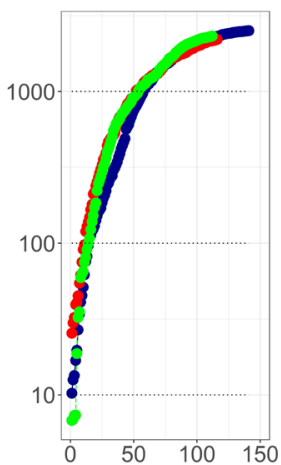

Alagoas

- Capital

- R. Metropolitana

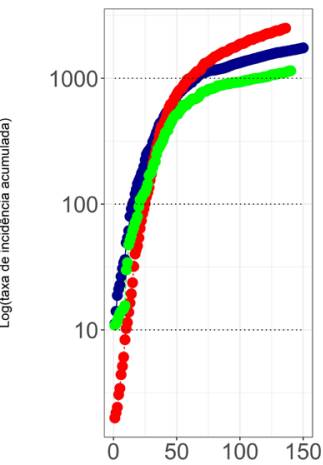

Maranhão

- Capital

- R. Metropolitana

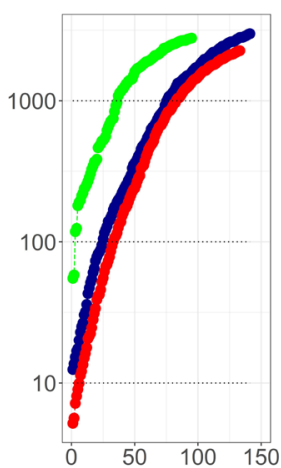

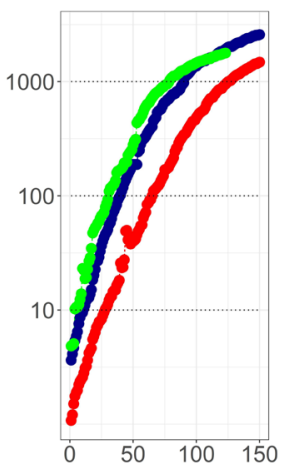

Bahia

- Capital

R. Metropolitana
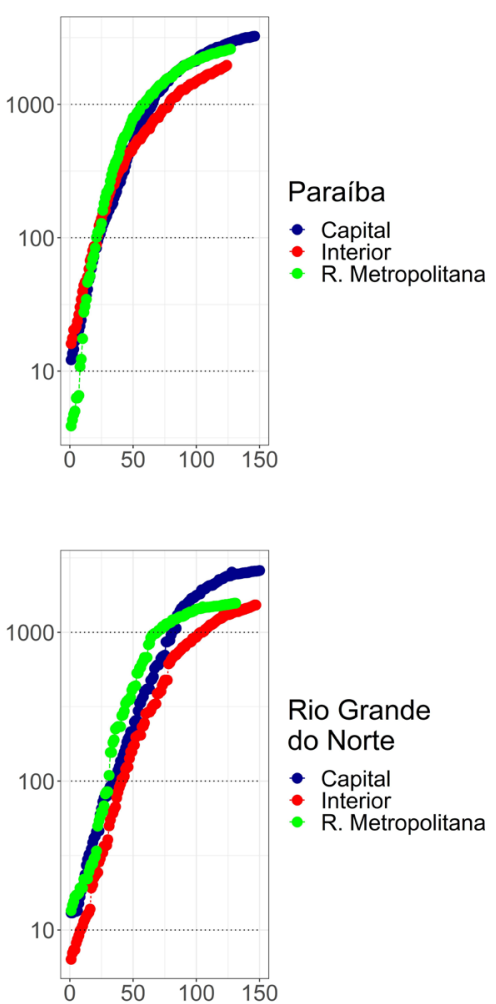
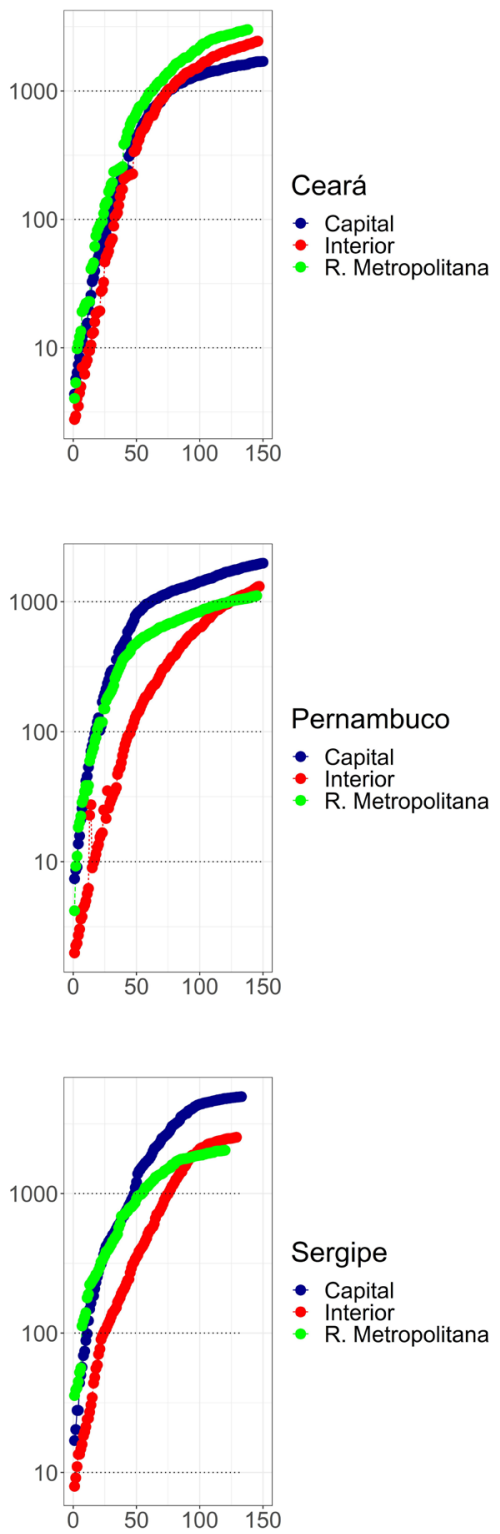

Figura 3. Taxa de incidência acumulada da COVID-19 a partir do $100^{\circ}$ caso para as capitais, regiões metropolitanas e para o interior dos Estados do Nordeste, 2020.

Fonte: Para casos- Cota, W. Wesley Cota, 2020. Monitoramento do número de casos de COVID-19 no Brasil. Disponível em : https://covid19br.wcota.me/. Acesso em: 2 de junho de 2020.

Para população- Freire, H.M.A., Gonzaga, M.R., Gomes, M.M.F. Projeções populacionais por sexo e idade para pequenas áreas no Brasil. Disponível em: https://revistarelap.org/index.php/relap/article/view/231. Acesso em: 2 de junho de 2020.

Ainda, nos diferentes estados, a capacidade instalada para realização de testagem molecular para detectar e isolar indivíduos infectados e pacientes com Covid-19, bem como para ras- trear seus contatos, era claramente insuficiente. Ademais, as taxas de ocupação de leitos de UTI eram superiores a $70 \%$ na maioria das capitais e estados. 


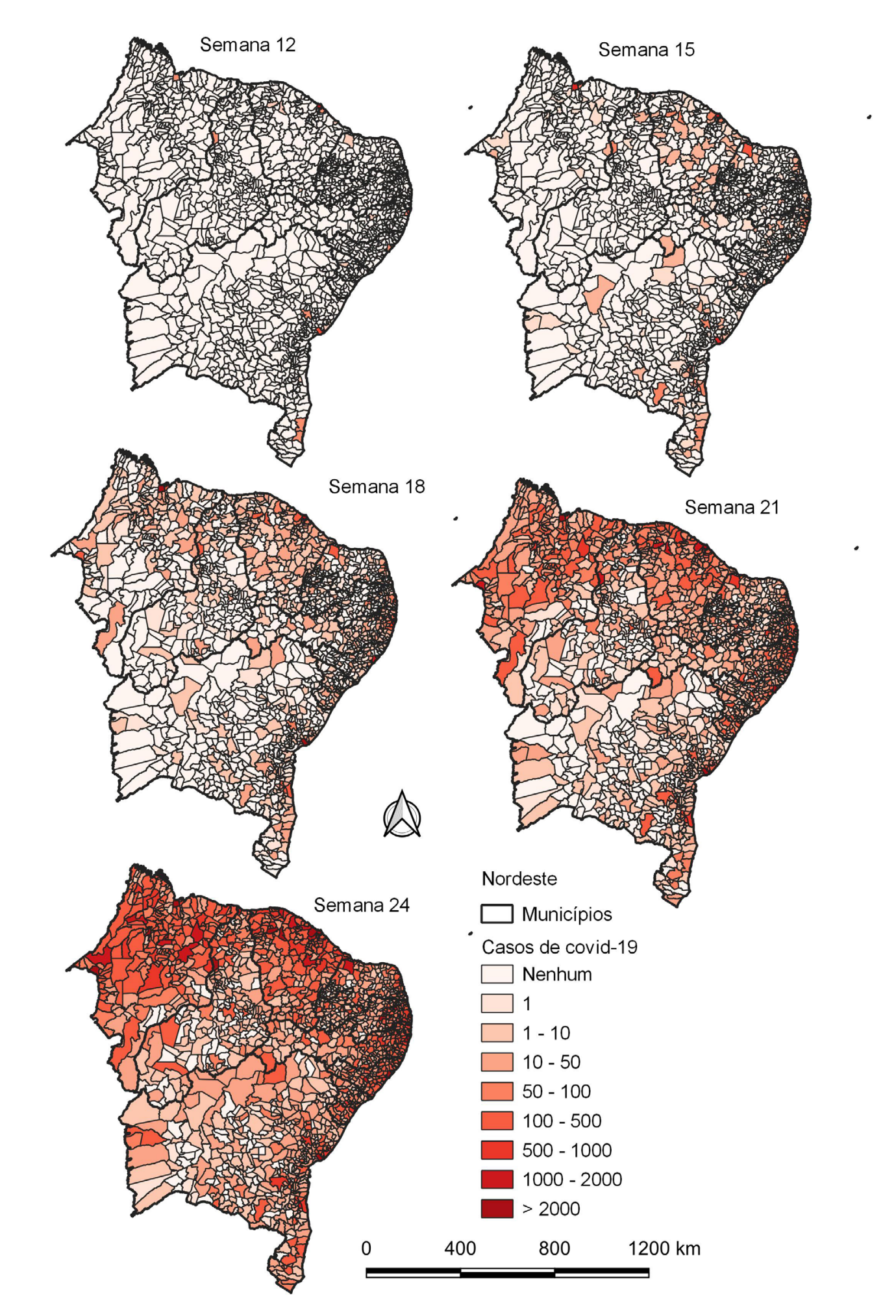

Figura 4. Expansão geográfica e temporal da epidemia da COVID-19 nos municípios do Nordeste da Semana Epidemiológica 12 até a Semana Epidemiológica 24. 

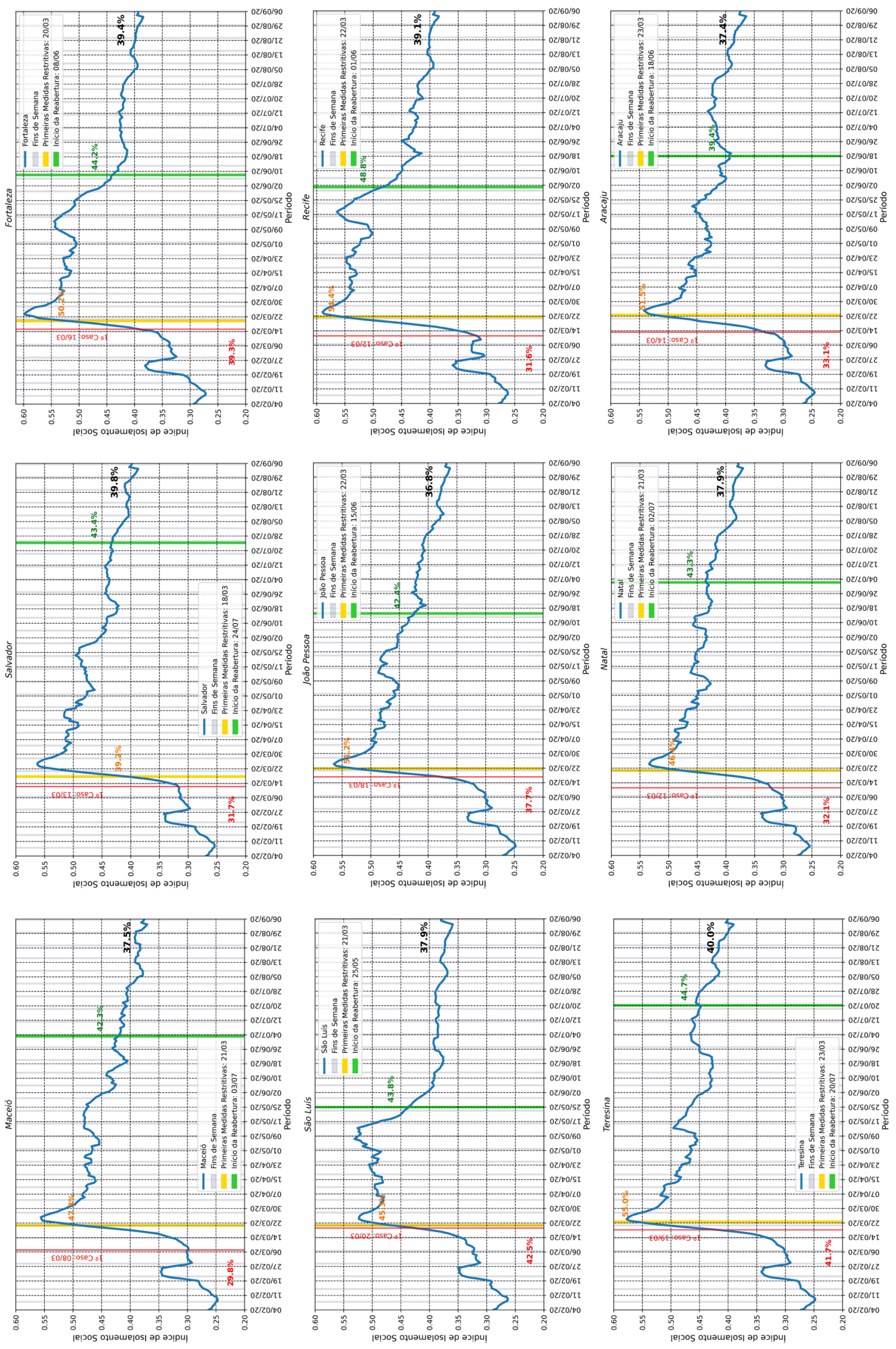

Figura 5. Índice de Isolamento Social nas Capitais do Nordeste até a Semana Epidemiológica 36. 
Nos 14 dias que antecederam o início das medidas de flexibilização do distanciamento social, a maioria das capitais dos estados do Nordeste não mostrava tendência decrescente dos casos e óbitos. Esta ocorreu em cenários epidemiológicos distintos nas diferentes capitais, tendo também, nesses locais, o curso da epidemia variado amplamente após o início da flexibilização. Quanto à mortalidade, para a maioria das capitais observou-se um platô por um período de pelo menos quatro semanas após o início da flexibilização. De maneira geral, não se evidenciou uma associação clara do aumento no número de casos ou óbitos com o início da flexibilização.

Pode-se considerar que a pandemia de Covid-19 se iniciou ao mesmo tempo nos vários estados da região Nordeste do país. Em que pese as similaridades, os estados apresentaram crescimento da epidemia, ainda que com velocidades de transmissão diferentes ${ }^{27}$, levando à intensificação das medidas de distanciamento, até chegar ao lockdown em algumas capitais. $\mathrm{O}$ pico da ocorrência de casos variou nas diferentes capitais, tendo, entretanto, ocorrido entre maio e julho. Ressalte-se que a ocorrência de casos, em geral, iniciou-se nos bairros mais abastados das capitais, para em seguida deslocar-se para as periferias, configurando cenários epidemiológicos diversos.

O objetivo do distanciamento social é diminuir a transmissão, o número de casos, os óbitos e a saturação do sistema de saúde. Em todo o mundo, pelo menos 186 países implementaram vários graus de restriçõos à circulação de pessoas, chegando ao lockdown em 82 deles $^{28}$. Ainda que estas medidas extremas tenham tido impacto efetivo, sua sustentação, ao longo do tempo, à espera de uma vacina eficaz, tem tido um alto custo econômico e social, impulsionando estratégias de reabertura e flexibilização. Entretanto, evidencias acumulam-se de que a flexibilização prematura pode desencadear o ressurgimento de infecções.

Tanto modelos matemáticos de predição $0^{29-34}$ como as análises de dados empíricos ${ }^{2,7}$ mostram benefícios do distanciamento social. Aparentemente não há uma regra geral de tempo ideal de distanciamento. Girona ${ }^{35}$ utilizou um modelo estocástico de Monte Carlo para estimar o tempo necessário de confinamento para evitar um rebote rápido da epidemia e sugere períodos de distanciamento que variam de 70 a 110 dias em grandes cidades americanas e da Europa.

Comparando distintos países asiáticos e europeus, é possível constatar variações no momento e no modo como as medidas foram adotadas e flexibilizadas, todavia as decisões governamentais basearam-se em uma combinação de critérios epidemiológicos, sanitários, econômicos e sociais $^{28}$. De um modo geral, os países asiáticos por terem vivido epidemias prévias de SARS e MERS, fortaleceram seus sistemas de saúde, têm mecanismos de rastreio e vigilância de casos mais desenvolvidos e adotam o uso de máscaras faciais de modo quase universal. Os países europeus, exceto a Alemanha, tiveram mais resistência inicial às medidas de contingência e, tão logo as flexibilizaram, assistiram a uma rápida expansão da circulação de pessoas, com o retorno às atividades de lazer em bares e outros locais públicos, especialmente com a chegada do verão. Como resultado, tem sido registrado o recrudescimento de casos de Covid-19, em vários países, principalmente em cidades da França, Espanha e Inglaterra. Madri, por exemplo, começou um segundo lockdown na noite de dois de outubro de 2020, o que motivou uma resposta judicial contradizendo a ação do governo central; a França também registrou na mesma data a maior alta de casos hospitalizados desde maio, e cidades como Paris e Lyon estão em alerta máximo; no Reino Unido, a região noroeste da Inglaterra está particularmente afetada ${ }^{36}$.

Os Estados Unidos, país de proporções continentais como o Brasil, mas com pior epidemia de Covid-19, apresenta um padrão caótico de reabertura e fechamento. A partir de $1^{\circ}$ de outubro, 28 estados adotaram oficialmente a reabertura, embora o que isso significa seja distinto por es$\operatorname{tado}^{37}$. Por exemplo, a Flórida reabriu em 4 de maio, levando a surtos graves durante o verão de mais de 10.000 casos por dia e o eventual fechamento de bares no final de junho. Um dos principais impulsionadores de novos casos foi a reabertura de escolas e universidades para instrução presencial à medida que o novo ano acadêmico começou $^{38}$. O Morbidity and Mortality Weekly Report do CDC registrou um aumento de 55\% dos casos no mês de agosto nos indivíduos na faixa etária de 18 a 22 anos $^{39}$. A reabertura teve uma motivação econômica e política. Do lado econômico, a parcela do orçamento escolar paga pelo estado tem diminuído drasticamente nos últimos 20 anos, obrigando as universidades a contar com mensalidades altas, que os alunos relutavam em pagar pelo ensino online. Do lado político, os legisladores estaduais republicanos insistiram no ensino presencial para apoiar a minimização da pandemia pelo presidente.

A comparação dos resultados do presente estudo com a situação de outros estados brasi- 
leiros também não é tarefa fácil. O Brasil é um país com vasto território e com muitas desigualdades regionais e sociais, que em razão das posições negacionistas do presidente da República, não implementou um plano nacional de enfrentamento da pandemia de Covid-19. Os esforços de articulação entre os governadores, no Consórcio Nordeste, parecem ter mitigado efeitos ainda mais danosos da pandemia ${ }^{27}$, a despeito de que alguns estados da região tenham sido duramente castigados.

O início da flexibilização das medidas de distanciamento em seis das nove capitais ocorreu após o pico da incidência, em duas coincidiu com o pico e em uma delas quando ainda apresentava uma tendência crescente. A situação epidemiológica e a capacidade de resposta do sistema de saúde não eram compatíveis com o início da flexibilização. Esse início em momento prévio ao que foi recomendado pela $\mathrm{OMS}^{11}$ e adotado por países asiáticos e europeus em condições bem mais favoráveis, pode ter sido precipitado pelos efeitos econômicos da pandemia, em contextos marcados pela alta proporção de trabalhadores informais e pela extrema pobreza ${ }^{40}$. As consequências dessas decisões são difíceis de serem previstas e devem ser cautelosamente monitoradas.

O início da flexibilização não se fez acompanhar de aumento no número de casos ou óbitos. É possível que níveis elevados de prevalência da infecção pelo SARSCoV-2 e, consequentemente, uma possível "imunidade de grupo", tenha contribuindo para explicar esse comportamento. Inquéritos realizados em dois estados do Nordeste, Ceará e Maranhão, mostraram que a prevalência de infecção em suas capitais atingiu 14\% e 38\%, em Fortaleza e São Luís, respectivamente ${ }^{41}$. Mais que isto, Fortaleza apresentou uma marcada diferença entre a prevalência de seus bairros, chegando a ter áreas mais ricas com prevalência de $4 \%$ enquanto que outras, com IDH muito mais baixos, esta foi de $24 \%$, ou seja, 6 vezes maior ${ }^{41}$. Estes são alguns indicadores que levam a pensar que seguimentos mais pobres da população, que compõem grande parte do estado e de suas capitais, poderiam estar promovendo algum tipo de “imunidade de grupo", protegendo outros seguimentos da população de estratos mais elevados que foram menos expostos, pela prática do distanciamento físico ${ }^{27}$.

A epidemia da Covid-19 atingiu o país num momento de uma crise política, econômica e social sem precedentes. A região Nordeste apresenta, tradicionalmente, os piores indicadores socioeconômicos. O distanciamento social de- pende não apenas da adesão da população, mas também do número de pessoas que residem nos domicílios, colocando a população das periferias urbanas em posição de maior vulnerabilidade. A exemplo de outras regiões do país, nas áreas de favelas onde vivem cerca de 13 milhões de Brasileiros o acesso à água limpa é limitado e as recomendações de distanciamento social virtualmente impossível ${ }^{42}$.

Apesar do limite mais aceito da imunidade de grupo estar entre 60 e $70 \%{ }^{43}$, alguns autores acreditam que este número possa ser bem menor ${ }^{44,45}$. Essa afirmativa tem sido baseada em modelos matemáticos e o limiar no qual a imunidade de grupo é atingida tem sido objeto de controvérsias. É possível que áreas com menores prevalências estejam vivendo uma instável estabilidade, que alguns autores têm chamado de bolhas ${ }^{46}$, que por sua vez podem ser "rompidas" a qualquer momento aumentando os casos de Covid-19.

Outro aspecto a ser considerado seria o uso em alta escala das máscaras caseiras que são, comprovadamente, barreiras que contribuem para redução da transmissão do vírus ${ }^{47,48}$. Pesquisadores também vêm levantando a hipótese de que o uso de máscaras reduziria a proporção de formas graves e das mortes, uma vez que, mesmo quando não impede o contágio, diminui o inoculum viral que pode estar relacionado à gravidade da forma clínica apresentada favorecendo o surgimento de casos leves e assintomáticos ${ }^{49}$.

Ainda, há que se considerar que as divergências de informação quanto à importância do distanciamento social, com clara oposição expressa pelo governo federal, cujo chefe de governo adotou uma postura de negação da epidemia. $\mathrm{O}$ "Índice de isolamento social"14, sugere que o declínio do distanciamento antecedeu o início das medidas de flexibilização, ou seja, o início oficial da flexibilização não aumentou, de forma importante, a interação entre as pessoas. Ressalte-se, ainda, que a flexibilização não ocorreu de forma completa, tendo sido programada para acontecer de forma progressiva.

A tendência da mortalidade após a flexibilização não apresentou variações semelhantes a incidência, permanecendo em platô por um período de tempo. Essa aparente dissociação pode ter, em parte, resultado de atraso na notificação dos óbitos por Covid-19 nos sistemas de informação, refletindo o atraso na obtenção do resultado da testagem.

A capacidade de testagem molecular para diagnóstico de Covid-19 nos diferentes estados do Nordeste é ainda muito limitada. Mesmo nos 
estados que realizaram maior número de teste para diagnóstico da Covid-19, Pernambuco, Bahia e Ceará, o quantitativo de testes realizados se mostrou insuficiente para assegurar a detecção dos casos na população e a dimensão da epidemia. Esta limitação tem duas implicações: a primeira é o efeito no registro oficial do número de casos e de óbitos pela doença, a segunda, e não menos importante, é na identificação precoce e isolamento de novos casos de doença ou de infecção, lacuna que é especialmente importante tanto para a definição do momento oportuno para a flexibilização do distanciamento, quanto para o monitoramento da epidemia no período posterior. Para tal é importante a testagem sistemática de casos suspeitos e seus contatos, para evitar ou conter o surgimento de novos brotes da epide$\mathrm{mia}^{50,51}$.

Nesse contexto seria necessário a rápida identificação dos casos, o rastreio dos contatos, e a disponibilização de locais para confinamento, como foi feito em países como Etiópia que enfrentam problemas similares ao Brasil neste quesito, e que transformou dormitórios das universidades em locais de isolamento ${ }^{52}$. Algumas limitações podem ser apontadas, tais como a subnotificação dos casos assintomáticos, leves e moderados por limitação na capacidade de testagem, além da orientação no início da pandemia para que apenas casos graves buscassem atendimento nas unidades de saúde. Na análise da tendência temporal e classificação das capitais segundo padrões epidemiológicos da Covid-19 foram utilizadas as datas de notificação, em virtude da ausência de registro da data do início dos sintomas em algumas capitais. O Índice de isolamento social expressa a movimentação da parcela da população usuária de celulares e, portanto, não pode ser inferido para toda população. Finalmente, apesar de ter havido uma busca por decretos nos sites dos governos estaduais e notícias na internet sobre os planos de reabertura de atividades, esta informação variou muito entre os estados e nem sempre foram localizadas com precisão as datas do início das medidas de flexibilização. $\mathrm{Na}$ maioria dos estados do nordeste essa data coincidiu para as capitais e Estados. Por outro lado, os resultados apresentados estão baseados nas notificações de casos e óbitos por Covid-19 que, também, fundamentaram às decisões dos gestores estaduais e municipais.

Implantar e manter políticas públicas mesmo quando respaldadas por bases científicas sólidas é um desafio, principalmente quando a pressão dos setores econômicos para que haja a retomada dos processos produtivos, do comércio e prestação de serviços ocorre em meio a um cenário de tragédia sanitária onde os dados da pandemia confirmam uma dura e inegável realidade. Medidas restritivas por algum tempo serão necessárias para prevenir recrudescimento da epidemia. Em termos absolutos o número de casos e óbitos ainda é elevado e o período de acompanhamento da epidemia é ainda muito reduzido, não sendo possível prever o que irá acontecer a médio e a longo prazo.

\section{Colaboradores}

Todos os autores contribuíram para as diferentes etapas da elaboração do artigo. 


\section{Referências}

1. World Health Organization (WHO). Coronavirus disease 2019 (COVID-19) Situation Report. Genebra: WHO; 2020.

2. Lau H, Khosrawipour V, Kocbach P, Mikolajczyk A, Schubert J, Bania J, Khosrawipour T. The positive impact of lockdown in Wuhan on containing the COVID-19 outbreak in China. J Travel Med 2020; 27(3):taaa037.

3. Aquino EML, Silveira IH, Pescarini JM, Aquino R, Souza-Filho JA. Social distancing measures to control the COVID-19 pandemic: Potential impacts and challenges in Brazil. Cien Saude Colet 2020; 25(1):24232446.

4. Ferguson NM, Laydon D, Nedjati-Gilani G, Imai N, Ainslie K, Baguelin M, Bhatia S, Boonyasiri A, Cucunubá Z, Cuomo-Dannenburg G, Dighe A, Dorigatti I, Fu H, Gaythorpe K, Green W, Hamlet A, Hinsley W, Okell LC, Van Elsland S, Thompson H, Verity R, Volz E, Wang H, Wang Y, Walker PGT, Walters C, Winskill P, Whittaker C, Donnelly CA, Riley S, Ghani AC. Impact of non-pharmaceutical interventions (NPIs) to reduce COVID-19 mortality and healthcare demand. Imp Coll COVID-19 Response Team 2020; 82(4):52.

5. Lewnard JA, Lo NC. Scientific and ethical basis for social-distancing interventions against COVID-19. Lancet Infect Dis 2020; 20(6):631-633.

6. Wilder-Smith A, Freedman DO. Isolation, quarantine, social distancing and community containment: Pivotal role for old-style public health measures in the novel coronavirus (2019-nCoV) outbreak. J Travel Med 2020; 27(2):taaa020.

7. Ji T, Chen H-L, Xu J, Wu L-N, Li J-J, Chen K, Qin G. Lockdown contained the spread of 2019 novel coronavirus disease in Huangshi city, China: Early epidemiological findings. Clin Infect Dis 2020; 71(6):14541460.

8. Brasil. Emenda Constitucional $n^{\circ} 95$, de 15 dezembro de 2016. Altera o Ato das Disposições Constitucionais Transitórias, para instituir o Novo Regime Fiscal, e dá outras providências. Diário Oficial da União 2016, 15 dez.

9. Instituto Brasileiro de Geografia e Estatística (IBGE). Pesquisa Nacional por Amostra de Domicílios Contínua - PNAD Contínua. Rio de Janeiro: IBGE; 2020.

10. Comitê Científico Consórcio Nordeste. Subcomitê de Epidemiologia. Pandemia da Covid-19 no Nordeste do Brasil: Situação Atual e Recomendações. Recife: UFPE; 2020.

11. Kluge HHP. Statement - Transition to a 'new normal' during the COVID-19 pandemic must be guided by public health principles. Copenhagen: WHO; 2020.

12. Instituto Brasileiro de Geografia e Estatística (IBGE). Painel de Indicadores. Rio de Janeiro: IBGE; 2020.

13. Cota W. Monitoring the number of COVID-19 cases and deaths in Brazil at municipal and federative units level. SciELO Preprints 2020. doi.org/10.1590/SciELOPreprints.362

14. Inloco. Mapa brasileiro da COVID-19. Recife: Inloco; 2020.

15. National Cancer Institute (NCI). Joinpoint Trend Analysis Software. Maryland: NCI; 2020.
16. Kim H, Fay MP, Feuer EJ, Midthune DN. Permutation tests for joinpoint regression with applications to cancer rates. Stat Med 2000; 19(3):335-351.

17. Costa NR. A Disponibilidade de Leitos em Unidade de Tratamento Intensivo no SUS e nos Planos de Saúde Diante da Epidemia da COVID-19 no Brasil. Rio de Janeiro: Escola Nacional de Saúde Pública Sergio Arouca; 2020.

18. Piauí. Secretaria de Saúde do Estado do Piauí (SESAPI). Boletim Epidemiológico Semanal COVID-19. Teresina: SESAPI; 2020.

19. Paraíba. Secretaria de Estado da Saúde (SES-PB). Boletim Epidemiológico. João Pessoa: SES-PB; 2020.

20. Alagoas. Secretaria de Saúde de Alagoas (Sesau). Informe Epidemiológico. Maceió: Sesau; 2020.

21. Ceará. Secretaria de Saúde (Sesa). Boletim epidemiológico. Fortaleza: Sesa; 2020.

22. Rio Grande do Norte. Secretaria de Estado da Saúde Pública (SESAP). Informe Epidemiológico Coronavírus (Covid-19). Natal: SESAP; 2020.

23. Pernambuco. Secretaria de Saúde de Pernambuco (SES-PE). Boletim Covid-19. Recife: SES-PE; 2020.

24. Bahia. Secretaria da Saúde do Estado da Bahia (Sesab). Boletim Epidemiológico Covid-19. Salvador: Sesab; 2020.

25. Sergipe. Secretaria de Estado da Saúde (SES-SE). Boletim Epidemiológico para atualização sobre o Covid-19. Aracaju: SES-SE; 2020.

26. Maranhão. Secretaria de Estado da Saúde do Maranhão (SES-MA). Boletim Epidemiológico Covid-19. São Luís: SES-MA; 2020.

27. Kerr L, Kendall C, Silva AAMD, Aquino EML, Pescarini JM, Almeida RLFD, Ichihara MY, Oliveira JF, Araújo TVB, Santos CT, Jorge DCP, Miranda-Filho DB, Santana G, Gabrielli L, Albuquerque MFPM, Almeida-Filho N, Silva NJ, Souza R, Ximenes RAA, Martelli CMT, Brandão Filho SP, Souza WV, Barreto ML. COVID-19 no Nordeste brasileiro: sucessos e limitações nas respostas dos governos dos estados. Cien Saude Colet 2020; 25(Supl. 2): 4099-4120.

28. Han E, Tan MMJ, Turk E, Sridhar D, Leung GM, Shibuya K, Asgari N, Oh J, García-Basteiro AL, Hanefeld J, Cook AR, Hsu LY, Teo YY, Heymann D, Clark H, McKee M, Legido-Quigley H. Lessons learnt from easing COVID-19 restrictions: an analysis of countries and regions in Asia Pacific and Europe. Lancet 2020; 396(10261):1525-1534.

29. Matrajt L, Leung T. Evaluating the Effectiveness of Social Distancing Interventions to Delay or Flatten the Epidemic Curve of Coronavirus Disease. Emerg Infect Dis 2020; 26(8):1740-1748.

30. Salje H, Tran Kiem C, Lefrancq N, Courtejoie N, Bosetti P, Paireau J, Andronico A, Hozé N, Richet J, Dubost CL, Le Strat Y, Lessler J, Levy-Bruhl D, Fontanet A, Opatowski L, Boelle PY, Cauchemez S. Estimating the burden of SARS-CoV-2 in France. Science 2020; eabc3517.

31. Chintalapudi N, Battineni G, Amenta F. COVID-19 virus outbreak forecasting of registered and recovered cases after sixty day lockdown in Italy: A data driven model approach. J Microbiol Immunol Infect 2020; 53(3):396-403. 
32. Zhang Y, Jiang B, Yuan J, Tao Y. The impact of social distancing and epicenter lockdown on the COVID-19 epidemic in mainland China: A data-driven SEIQR model study. medRxiv 2020 [Publicação antecipada]. doi.org/10.1101/2020.03.04.20031187

33. Prem K, Liu Y, Russell TW, Kucharski AJ, Eggo RM, Davies N, Centre for the Mathematical Modelling of Infectious Diseases COVID-19 Working Group, Jit M, Klepac P. The effect of control strategies to reduce social mixing on outcomes of the COVID-19 epidemic in Wuhan, China: a modelling study. Lancet Public Heal 2020; 5:e261-e270.

34. Courtemanche C, Garuccio J, Le A, Pinkston J, Yelowitz A. Strong Social Distancing Measures In The United States Reduced The COVID-19 Growth Rate. Health Aff 2020; 39(7):10.1377/hlthaff.

35. Girona T. Confinement Time Required to Avoid a Quick Rebound of COVID-19: Predictions From a Monte Carlo Stochastic Model. Front Phys 2020; 8:186.

36. UOL Notícias. Coronavírus. França bate novo recorde e sinaliza 'segunda onda' do coronavírus na Europa [Internet]. 2020 [acessado 2020 Out 11]. Disponível em: https://noticias.uol.com.br/ultimas-noticias/rfi /2020/10/11/franca-bate-novo-recorde-de-casos-decovid-19-em-meio-a-alta-de-casos-na-europa.html

37. The New York Times. See How All 50 States Are Reopening (and Closing Again) [Internet]. 2020 [acessado 2020 Out 16]. Disponível em: https://www.nytimes. com/interactive/2020/us/states-reopen-map-coronavirus.html

38. The Chronicle of Higher education. Live Coronavirus Updates: Here's the Latest [Internet]. 2020 [acessado 2020 Out 7]. Disponível em: https://www.chronicle. com/article/live-coronavirus-updates-heres-the-latest?cid=gen_sign_in

39. Salvatore PP, Sula E, Coyle JP, Caruso E, Smith AR, Levine RS, Baack BN, Mir R, Lockhart ER, Tiwari TSP, Dee DL, Boehmer TK, Jackson BR, Bhattarai A. Recent Increase in COVID-19 Cases Reported Among Adults Aged 18-22 Years - United States, May 31 September 5, 2020. MMWR Morb Mortal Wkly Rep 2020; 69(39):1419-1424.

40. Instituto Brasileiro de Geografia e Estatística (IBGE). Sintese de Indicadores Sociais: uma análise das condições de vida da população brasileira. Rio de Janeiro: IBGE; 2019.

41. Ceará. Secretaria da Saúde do Estado do Ceará e Secretaria Municipal de Saúde de Fortaleza. Inquérito soroprevalência coronavírus em Fortaleza. Fortaleza: Secretaria da Saúde do Estado do Ceará/Secretaria Municipal de Saúde de Fortaleza; 2020.

42. Burki T. COVID-19 in Latin America. Lancet Infect Dis 2020; 20(5):547-548.

43. Randolph HE, Barreiro LB. Herd Immunity: Understanding COVID-19. Immunity 2020; 52(2):737-741.
44. Aguas R, Corder RM, King JG, Goncalves G, Ferreira MU, Gomes MGM. Herd immunity thresholds for SARS-CoV-2 estimated from unfolding epidemics. medRxiv 2020. [publicação antecipada]. doi. org/10.1101/2020.07.23.20160762

45. Britton T, Ball F, Trapman P. A mathematical model reveals the influence of population heterogeneity on herd immunity to SARS-CoV-2. Science 2020; 369(6505):846-849.

46. Pinto JPG, Magalhães PC, Figueiredo GM, Alves D, Segura-Angel DM. Local protection bubbles: an interpretation of the decrease in the velocity of coronavirus's spread in the city of São Paulo. medRxiv 2020 [publicação antecipada]. doi. org/10.1101/2020.08.11.20173039

47. Eikenberry SE, Mancuso M, Iboi E, Phan T, Eikenberry K, Kuang Y, Kostelich E, Gumel AB. To mask or not to mask: Modeling the potential for face mask use by the general public to curtail the COVID-19 pandemic. Infect Dis Model 2020; 5:293-308.

48. Stutt RO, Retkute R, Bradley M, Gilligan CA, Colvin J. A modelling framework to assess the likely effectiveness of facemasks in combination with 'lock-down' in managing the COVID-19 pandemic. Proc R Soc 2020; A476:20200376.

49. Gandhi M, Rutherford GW. Facial Masking for Covid-19 - Potential for "Variolation" as We Await a Vaccine. N Engl J Med 2020; 383(18):e101.

50. Wu J, Tang B, Bragazzi NL, Nah K, McCarthy Z. Quantifying the role of social distancing, personal protection and case detection in mitigating COVID-19 outbreak in Ontario, Canada. J Math Ind 2020; 10(1):15.

51. Yezli S, Khan A. COVID-19 social distancing in the Kingdom of Saudi Arabia: Bold measures in the face of political, economic, social and religious challenges. Travel Med Infect Dis 2020; 37:101692.

52. Oqubay A. Ethiopia's unconventional COVID-19 response [Internet]. Project Syndicate; 2020 [acessado 2020 Jul 19]. Disponível em: https://www.project-syndicate.org/commentary/ethiopia-successful-unconventional-covid 19-response-by-arkebe-oqubay-2020-05?barrier=accesspaylog

Artigo apresentado em 24/07/2020

Aprovado em 07/01/2021

Versão final apresentada em 09/01/2021

Editores-chefes: Romeu Gomes, Antônio Augusto Moura da Silva 